\title{
4 \\ O USO DAS TICS E APRENDIZAGEM FLEXÍVEL: CONTRIBUIÇÕES AO DEBATE CRÍTICO
}

\author{
The use of TICs and flexible learning: contributions to the critical debate
}

\author{
Taise Cristina Gomes Clementino Negreiros * \\ https://orcid.org/0000-0002-4404-2398
}

\begin{abstract}
RESUMO
Neste artigo discutimos sobre as novas formas de aprendizagem postas à classe trabalhadora diante do espraiamento do uso das TICs na totalidade da vida social. Partimos da hipótese de que, no contexto de acumulação flexível, o uso das TICs é fulcral para a redefinição da educação através de processos de aprendizagens flexíveis efetivados mediante novas estratégias pedagógicas e do redimensionamento do espaço e do tempo necessários à formação dos sujeitos, conforme as necessidades reprodutivas do capital e necessidade de recomposição do poder hegemônico burguês. Para isto, estudamos autores clássicos do pensamento crítico marxista e autores brasileiros contemporâneos que discutem a temática em questão.
\end{abstract}

\section{PALAVRAS-CHAVE}

Tecnologias da informação e comunicação. Aprendizagem. Regime de acumulação flexível.

\section{ABSTRACT}

In this article we aim to analyze the new forms of learning put to the working class before the spread of the use of the TICs in the totality of the social life. We assume that, in the context of flexible accumulation, the use of ICTs is central to the redefinition of education through flexible learning processes carried out through new pedagogical strategies and the re-dimensioning of space and time necessary for the training of subjects, according to the reproductive needs of capital. For this, we study classic authors of critical Marxist thinking and contemporary Brazilian authors who discuss the subject in question.

\section{KEY WORDS}

Information and communication technologies. Learning. Flexible accumulation regime.

Submissão: 23/3/2021.

Aceito em: 11/6/2021

\footnotetext{
* Assistente Social. Doutora pelo Programa de Pós-Graduação em Serviço Social da Universidade Federal de Pernambuco (UFPE, Recife, Brasil). Professora Adjunta do Departamento de Serviço Social da Universidade de Brasília (SER-UNB, Brasília (DF), Brasil). UnB, Campus Universitário Darcy Ribeiro, Instituto Central de Ciências (ICC NORTE, Asa Norte, Brasília (DF), CEP.: 70910-900 E-mail: taise_negreiros@hotmail.com.
}

DOI 10.22422/temporalis.2021V21n41p102-118 material em qualquer suporte ou formato, bem como adaptar, transformar e criar a partir deste material para qualquer fim, mesmo que comercial. O licenciante não pode revogar estes direitos desde que você respeite os termos da licença. 


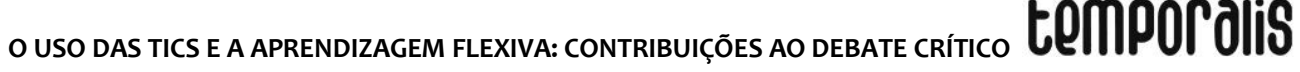

\section{INTRODUÇÃO}

$\mathrm{O}$ presente artigo é fruto do processo de pesquisa de doutorado, cujo objetivo foi apreender as mediações político-econômicas, culturais e pedagógicas do uso das Tecnologias da Informação e Comunicação (TICs) nas novas formas de aprendizagem que emergem a partir de uma conjuntura marcada pelo espraiamento do uso dessas tecnologias na totalidade da vida social.

A partir dos estudos de Mandel (1985), compreendemos que as revoluções tecnológicas se constituem em um elemento fundamental da dinâmica capitalista desde os seus primórdios. As constantes inovações dos meios de produção é uma condição básica para o desenvolvimento capitalista e à garantia de ganhos cada vez mais acentuados de produtividade e lucro. Portanto, o desenvolvimento tecnológico se constitui um elemento estrutural da dinâmica capitalista e um recurso essencial para a superação das crises.

As transformações decorrentes da incorporação dessas tecnologias não se restringem ao campo específico da produção. Estas também provocam mudanças no âmbito das relações sociais dentro e fora do processo produtivo, que ultrapassam os limites das dimensões econômicas e se estendem por todas as dimensões da vida social: nas relações políticas, culturais e até mesmo nas inter-relações pessoais que os indivíduos estabelecem entre si.

As práticas educativas, nesse contexto, exercem mediação fundamental para disseminação de conhecimentos e valores necessários tanto à adequação cognitiva e laborativa dos sujeitos às demandas do processo produtivo, quanto à formação de intelectuais necessários para a criação e divulgação dos novos conhecimentos que darão sustentação teórica e ideológica à nova dinâmica societária emergente.

Atualmente, identificamos recorrentes manifestações de diversos intelectuais orgânicos da classe burguesa no campo educacional - dentre eles organismos internacionais como a Organização das Nações Unidas para a Educação, a Ciência e a Cultura (UNESCO, 2016) e Banco Mundial (2011) - de que o uso das TICs se torna imprescindível para garantir um processo formativo mais adequado às exigências do mercado. Estratégias pedagógicas como educação híbrida, inovação disruptiva e sala de aula invertida - todas elas mediadas pelo uso das TICs - ganham destaque no atual cenário educacional.

Diante dessas reflexões, compreendemos que a intensificação do uso das TICs no campo educacional se constitui em uma importante estratégia para reformular os processos de formação profissional, em uma conjuntura marcada por frenéticas transformações nas quais o conhecimento e a informação são considerados elementos voláteis, cuja apropriação torna-se cada vez mais obsoleta.

\section{O USO DAS TICS NO REGIME DE ACUMULAÇÃO FLEXÍVEL E AS NOVAS DETERMINAÇÕES POSTAS À FORMAÇÃO PROFISSIONAL DA CLASSE TRABALHADORA.}

Ao longo da história podemos perceber a necessidade de se reconfigurar o processo formativo/educativo dos sujeitos sociais, de modo a readequar tal processo às constantes mudanças da sociabilidade do capital que necessita, constantemente, recriar formas (políticas, econômicas e culturais) de legitimação dos interesses da classe burguesa e 
alcance do consenso e coesão social. Como afirma Dias (2012), a educação "[...] é peça fundamental nesse processo de deslegitimação das forças do trabalho [...]” (DIAS, 2012, p. 331), um mecanismo de assimilação de poder, sendo uma mediação necessária para a legitimação dos interesses da classe dominante e reprodução de seus valores e modos de vida.

Gramsci (2007), ao discutir o modelo fordista de produção, analisa o processo de formação de um novo tipo de homem necessário a uma dinâmica societária pautada no, até então, novo padrão produtivo fordista. O autor evidencia diversas estratégias utilizadas para "conformar os instintos" da força humana de trabalho às novas relações de produção baseada na intensa racionalização e disciplina no processo de trabalho.

A criação de instrumentos de inspeção para controlar a "moralidade" dos trabalhadores como, por exemplo, o policiamento de sua vida sexual - se constitui em estratégias de adequação psicofísica da força de trabalho humana à nova dinâmica industrial. As novas formas de viver, impostas à classe trabalhadora na sociedade americana, conformam uma nova forma de controle ideológico-cultural e ético-política para o desenvolvimento do modo de produção capitalista que tem no modelo fordista de produção a sua base técnicoprodutiva (GRAMSCI, 2007).

A organização dos processos educativos no âmbito escolar se torna fundamental de modo a adequar, desde a infância, os novos hábitos necessários à lógica de reprodução capitalista. O rigor na disciplina, na compostura, o cumprimento dos horários e necessidade do domínio de conhecimentos e habilidades relacionadas ao mundo do trabalho se torna primordial como forma de garantir que as relações sociais estabelecidas no âmbito da instituição escolar antecipassem as relações próprias da industrialização sob a qual os indivíduos passariam a conviver (ENGUITA, 2004).

Portanto, a organização do processo educativo será delineada hegemonicamente pela classe burguesa dominante que mobilizará os aparelhos privados de hegemonia e o próprio Estado para conformar seu projeto hegemônico de classe. A atuação estatal nesse processo torna-se essencial uma vez que a classe burguesa precisa difundir seu domínio e influência também na esfera da superestrutura, expandindo seu domínio hegemônico enquanto um projeto societário à classe subalterna, mistificando, assim, seus interesses específicos de classe (BIANCHI, 2008).

As políticas educacionais formuladas e geridas no âmbito do Estado têm um direcionamento de domínio de classe definido, mesmo que, em seu discurso imediato, transpareça a defesa de que se estaria atendendo aos interesses e necessidade dos subalternos. O que não é de todo falso. Todavia, a concessão à classe trabalhadora do acesso aos sistemas educacionais se limitará aos aspectos necessários à reprodução dos interesses da classe dominante, contribuindo na consolidação das relações de hegemonia e atuando para o alcance da coesão e do consenso necessários à reprodução da sociedade.

Não obstante, ressaltamos que a educação nos marcos da sociabilidade capitalista se constitui em um campo contraditório, tendo em vista que ele é imprescindível para o processo de disputa hegemônica entre as classes socialmente antagônicas. Torna-se fundamental, para a classe subalterna, o acesso aos sistemas de ensino formal enquanto estratégia preliminar para a aquisição do conhecimento sócio-historicamente produzido

Temporalis, Brasília (DF), ano 21, n. 41, p. 102-118, jan./jun. 2021. | ISSN 2238-1856 
pela humanidade e sua apreensão a partir de uma análise crítica, de modo que a possibilite desvendar as mistificações postas na vida cotidiana e, sobretudo, as determinações intrínsecas à dinâmica das relações sociais no âmbito da sociabilidade capitalista e reconhecer a sua inserção nesta enquanto classe.

Esses apontamentos são importantes para compreendermos como se efetiva o processo de institucionalização dos processos formativos/educativos da classe trabalhadora em cada estágio do desenvolvimento do modo de produção capitalista; as tendências das políticas geridas no âmbito estatal; as formas organizativas dos espaços escolares e a redefinição dos conhecimentos necessários à formação específica da classe trabalhadora a partir da nova lógica reprodutiva e acumulativa implementada pelo capital a partir dos anos 1970.

Conhecida como processo de reestruturação produtiva, ela se efetiva a partir do regime de acumulação flexível o qual tem por principal característica o confronto direto com a rigidez fordista, pautando-se na flexibilidade dos processos e nas relações de trabalho mediadas pelo uso e desenvolvimento de novas tecnologias.

Ela desencadeou um conjunto de mudanças necessárias ao processo de reconversão da produção e das relações sociais, cujo objetivo fora possibilitar novas estratégias de superação da crise que assolou o modo de produção capitalista neste período. Deste modo, foi fundamental a mediação do uso de novas tecnologias que - através do acelerado desenvolvimento da microeletrônica - se expandiu para as diversas instâncias da vida social, contribuindo para a instauração de uma nova e complexa dinâmica no âmbito das relações sociais.

A inserção das novas tecnologias no processo produtivo possibilitou a criação de mercadorias especializadas, voltadas para as demandas do mercado; a intensificação da substituição da força viva de trabalho e a flexibilização das relações trabalhistas, em processos que foram fundamentais para aceleração do tempo de giro do capital e, consequentemente, para a sua valorização e retomada das altas taxas de lucro.

Nesse cenário, a disseminação do uso das Tecnologias da Informação e Comunicação nas mais variadas instâncias da vida social, contribuiu para a consolidação de uma nova dinamicidade da vida cotidiana, caracterizadas pela aceleração dos ritmos dos processos econômicos e dos próprios processos sociais que alteraram, significativamente, as formas de pensar, sentir e agir dos sujeitos.

Conforme afirma Harvey (2008), a partir dos anos 1970 vivenciamos uma sociedade do descarte, na qual "[...] mais do que jogar fora bens produzidos [...]; significa também ser capaz de atirar fora valores, estilos de vida, relacionamentos estáveis, apego às coisas, [...] modos adquiridos de agir e de ser"' (HARVEY, 2008, p. 258).

Estas mudanças no campo socioeconômico tiveram o suporte de novas tendências políticas e ideoculturais que proporcionaram a sua disseminação e reprodução em âmbito mundial. No campo político, há a emersão da política neoliberal a qual tem por princípio a defesa do livre comércio e do livre funcionamento das instituições como principal mote regulador da economia global e da vida social (HARVEY, 2008). Esses ajustes impõem a 
adoção de diversas medidas, tais como desregulamentação de direitos, cortes nos gastos sociais com políticas públicas, acirramento das privatizações dos serviços públicos, além de diversas concessões à livre atuação do capital financeiro.

Nesse contexto, a reformulação da atuação do Estado foi fundamental para efetivação desses ajustes. Este, sob o discurso neoliberal, deixaria de intervir na regulação da economia e do mercado financeiro, garantindo, assim, a livre ação do comércio e a atuação da "mão invisível" do mercado como principais elementos reguladores da vida social.

Segundo o ideário neoliberal, as políticas sociais são caracterizadas ideologicamente como paternalistas e geradoras de despesas (BEHRING, 2003), sendo a defesa por suas privatizações como principal estratégia de romper com os entraves burocráticos estatais e, assim, garantir maior eficiência e produtividade dos serviços. É importante ressaltar que o discurso proponente da privatização se pauta no argumento de uma "crise fiscal" no orçamento público cujo motivo principal seria, segundo o discurso neoliberal, os altos gastos sociais.

Por fundamento ideológico, teremos o surgimento das teses da Sociedade da Informação ou Sociedade do Conhecimento. Estas partem da premissa de que a informação e o conhecimento são elementos centrais para o desenvolvimento socioeconômico da sociedade. Tais mudanças, a partir desta perspectiva, se constituem no elemento central para a modernização da formação da classe trabalhadora no país e de integração deste na "sociedade da informação" (LIMA, 2007).

A partir das análises de autores como Massuda (1982) e Schaff (1995), podemos compreender que o principal argumento que eles apresentam em comum é de que a automatização e informatização dos processos produtivos, além do exponencial uso das novas tecnologias em todas as dimensões da vida social, seriam capazes de superar as desigualdades sociais, fomentando, assim, uma sociedade mais igualitária.

Contudo o que embasa as reflexões presentes nas teses que defendem uma "Sociedade da Informação" ou "Sociedade Informática" é a defesa da ciência e tecnologia enquanto principal fator produtivo e a negação do trabalho como categoria fundante do ser social e do proletário como classe revolucionária (LESSA, 2007). Os progressos no âmbito da vida social se realizariam nos marcos do próprio modo de produção capitalista.

Ao negar a centralidade do trabalho enquanto categoria fundante do ser social e as particularidades que este assume nos marcos da sociabilidade capitalista, cuja base fundante está na apropriação privada dos meios de produção e da riqueza socialmente produzida, a defesa pelo predomínio das tecnologias na vida social conduz a uma análise neutra das dinâmicas societárias - próprias das teorias positivistas - destituindo-as da compreensão do conflito de classes que as constituem (LESSA, 2007).

Portanto, a principal afirmação utilizada pelos autores que propagam o "fim da sociedade industrial" e o advento de uma "Sociedade da informação" é de que as transformações tecnológicas - com a crescente automação dos processos produtivos e disseminação do uso das TICs em todas as dimensões da vida social - são capazes de promover alterações na sociedade e nas relações sociais de produção contribuindo, portanto, para a supressão do antagonismo de classe. 
O que evidenciamos com essas premissas é uma fetichização da técnica, sendo a sua análise descolada dos determinantes socioeconômicos e políticos da sociabilidade na qual ela está inserida. Conforme explicita Lessa (2007), o desenvolvimento tecnológico é consequência das necessidades reprodutivas de cada modo de produção, e não a sua causa. Portanto, o "[...] momento predominante não se localiza na técnica em si, mas nas relações sociais que a determinam" (LESSA, 2007, p. 257).

As tecnologias no âmbito da sociabilidade capitalista são utilizadas a partir de uma estrutura política e econômica que reforça os padrões de dominação existentes. A intensificação do seu uso nos processos produtivos não erradicou as relações de opressão da classe trabalhadora, mas sim intensificou a exploração da força humana de trabalho que, para além do desgaste de sua energia física, se torna necessário o uso da sua potencialidade psíquica-intelectiva.

A partir desse cenário são demandadas reformulações no processo educativo da classe trabalhadora, tanto no campo das políticas públicas, quanto no próprio processo de organização do ensino-aprendizagem, de modo a adequá-los às transformações no modo de produção e reprodução das relações sociais no capitalismo.

Nessa perspectiva, emergem novas estratégias de disciplinamento da força humana de trabalho, de modo a adequá-la a um contexto no qual o acelerado processo de destruição e reconstrução de habilidades, se torna fundamental para as novas demandas de acumulação capitalista. Faz-se necessário formar trabalhadores flexíveis, que acompanham as mudanças decorrentes da dinamicidade tecnológica, científica e contemporânea, sendo capazes de desenvolver qualidades subjetivas que se adeque a processos de trabalho cada vez mais instáveis e precarizados (KUENZER, 2007).

No Brasil, podemos observar estas tendências a partir das políticas adotadas no âmbito educacional - políticas estas geridas a partir das orientações propostas por organismos internacionais, como Banco Mundial (BM) e Organização das Nações Unidas para a Educação, Ciência e Cultura (Unesco).

Destacamos, por exemplo, as orientações tecidas pelo Banco Mundial (BM) ao Estado brasileiro, para a reorganização do ensino de nível superior e das demais políticas educacionais brasileiras. Segundo Sguissardi (2009), sob o argumento de que a atual gestão dos sistemas de ensino seria ineficaz para atender à demanda de expansão e qualificação de profissionais necessários ao mercado de trabalho, o BM definiu diversas sugestões que tinham por base a defesa do investimento na educação básica como principal estratégia de desenvolvimento dos países periféricos; a promoção da diversificação das instituições de Ensino Superior e; no incentivo do crescimento do Ensino Superior brasileiro através de instituições privadas.

Portanto, a partir nos anos 1990 e 2000 ocorre a intensificação da privatização do Ensino Superior brasileiro com forte presença do capital estrangeiro ${ }^{1}$, o que retrata a dependência

\footnotetext{
${ }^{1}$ Mancebo (2015) destaca que, nos anos 2000, o crescimento da iniciativa privada pode ser evidenciado: através da criação de grandes conglomerados educacionais; a financeirização, com os investimentos desses
}

Temporalis, Brasília (DF), ano 21, n. 41, p. 102-118, jan./jun. 2021. | ISSN 2238-1856 
histórica desse país frente ao mercado internacional e a aliança estratégica entre a burguesia brasileira e a burguesia internacional para a manutenção dos seus interesses econômicos e políticos.

Em relação à utilização das TICs nos processos de formação profissional, esta irá se efetivar em duas dimensões: onde a primeira remete à defesa do uso das TICs enquanto principal agente do desenvolvimento econômico e social, sendo seu uso, portanto, imprescindível à promoção de estratégias para ampliação do acesso dos indivíduos aos mais diversos níveis de ensino e para a "inclusão social”.

A segunda reporta à defesa de que somente através da mediação do uso das TICs no processo educativo, poderíamos garantir um novo processo de aprendizagem, adequado a uma realidade marcada por novas formas de socialização, baseada no avanço das tecnologias informacionais e dos recursos da internet que demandam novos conhecimentos e competências aos sujeitos que desejam se inserir no mercado de trabalho.

Sobre o uso das TICs como agente promotor do desenvolvimento e da inclusão social, destacamos os estudos elaborados pelo BM e Unesco os quais definem diversas orientações, sobretudo aos países considerados em desenvolvimento, sobre as principais medidas e estratégias a serem adotadas por esses países de modo a readequarem suas políticas educacionais e, com isso, melhorar a qualidade dos seus sistemas de ensino.

Para estas instituições, o desenvolvimento das inovações tecnológicas e seu uso no campo educacional seriam peças fundamentais para o desenvolvimento socioeconômico dos países, conforme as novas prerrogativas impostas pelo processo de reestruturação produtiva ora em curso, compatibilizando transformação produtiva, democracia e equidade social, contribuindo assim, para uma maior competitividade desses fatores no cenário internacional (FERREIRA, 2013).

Nessa perspectiva, as TICs serão incorporadas no Ensino Superior brasileiro como estratégia de desenvolvimento de pesquisas e inovações como consequência da constante incorporação da ciência no processo produtivo no regime de acumulação flexível, tornando as instituições universitárias prisioneiras das transações de lucro para o capital² e; como estratégia para a expansão de IES, sob o discurso de promoção da democratização do acesso ao ensino superior mediante regulamentação e expansão dos cursos na modalidade de Ensino a Distância³.

conglomerados na Bolsa de Valores e; a internacionalização das instituições de ensino com a participação do capital estrangeiro.

${ }^{2}$ Conforme as análises de Mandel (1982), a partir do século XX - mais especificamente durante o período da II Guerra Mundial e ao subsequente período de Guerra Fria - há uma intensificação das atividades voltadas à pesquisa que passa a assumir a forma de uma empresa independente, organizando-se sistematicamente como um negócio específico com bases capitalistas. Portanto, o desenvolvimento de pesquisas e inovações passa a ser subjugado aos interesses e necessidade da acumulação capitalista.

3 A modalidade de Ensino a Distância no país foi regulamentada em 2005. Será em 2005 que, através do Decreto $n^{\circ} 5622$ do MEC, que o EaD é regulamentado no país, após quase dez anos de seu primeiro marco legal na LDB de 1996. Atualmente, este Decreto n. 5622 foi revogado pelo Decreto n. ${ }^{\circ} 9057$, de 25 de maio de 2017, o qual traz significativas mudanças no processo de credenciamento das instituições EaD no país, dentre as quais podemos destacar: a criação dos polos presenciais estará subjugada à natureza do curso a ser ofertado; possibilidade de credenciamento de instituições exclusivamente para a modalidade de ensino à 
Compreendemos que a expansão dessa modalidade de ensino está vinculada às necessidades reprodutivas do capital na busca de novos lócus de extração de lucros e na demanda por uma força de trabalho qualificada, a qual impõe aos diversos sujeitos a exigência por maiores níveis de qualificação, sendo exaltado pelo discurso governamental o seu caráter democratizante.

Esse também é um dos principais argumentos dos intelectuais orgânicos que propagam o uso da TICs particularizado na modalidade de Ensino a Distância. Para estes, o EaD se constitui na modalidade de ensino que melhor se adequa a uma conjuntura marcada pelo intenso desenvolvimento tecnológico e crescimento exponencial de informações. Conforme afirma Belloni (2005)

\begin{abstract}
A EaD tende, doravante, a se tornar cada vez mais um elemento regular e necessário dos sistemas educativos, não apenas para atender a demandas ou grupos específicos, mas também para desempenhar funções de crescente importância, especialmente no ensino pós-secundário, ou seja, na educação da população adulta, o que inclui o ensino superior regular e toda a grande e variada demanda de formação contínua gerada pela obsolescência acelerada da tecnologia e do conhecimento (BELLONI, 2005, p. 189).
\end{abstract}

A defesa da modalidade EaD também está organicamente vinculada à segunda tendência do uso das TICs na política educacional brasileira que Kuenzer (2016), irá definir por aprendizagem flexível. Esta surge como uma das expressões do projeto pedagógico da acumulação flexível a qual exige transformações importantes no processo educativo dos trabalhadores, tanto no âmbito da organização estrutural e pedagógica das instituições, quanto no campo curricular.

Em relação às mudanças no campo curricular, podemos destacar a valorização de uma formação generalista, que possibilite aos sujeitos o desenvolvimento de aspectos comportamentais, tais como a criatividade, adaptabilidade, capacidade de resolução de problemas complexos e iniciativa, o desenvolvimento da autonomia e da capacidade de "aprender ao longo da vida" (KUENZER, 2007; KUENZER, 2016).

Quanto aos aspectos estruturais, destacamos a exaltação do uso das TICs na educação, enquanto um elemento imprescindível à conformação de um novo processo de aprendizagem condizente com as demandas postas no regime de acumulação flexível, cujas principais características são: o uso de recursos das mídias; a busca por novas estratégias e metodologias de ensino; flexibilização do acesso aos conhecimentos e ao processo de ensino com o recurso da internet e; versatilidade na relação com o tempoespaço no processo de ensino e aprendizagem.

Alves (2011) irá caracterizar esse contexto como a Quarta Idade da Máquina, na qual o desenvolvimento das TICs possibilita uma interação totalmente nova entre homemmáquina, conformando um novo espaço de sociabilidade virtual apropriado pelo capital, o ciberespaço. Para o autor, esse novo espaço é um campo de integração flexível e difusa

distância e; a possibilidade de parcerias entre instituições EaD e outros instituições jurídicas (que poderão ser instituições de ensino básico ou técnico-profissional).

Temporalis, Brasília (DF), ano 21, n. 41, p. 102-118, jan./jun. 2021. | ISSN 2238-1856 
dos fluxos de informação e de comunicação entre as máquinas computadorizadas, um novo complexo mediador entre os homens o qual, baseado em dispositivos técnicos, conforma um novo espaço de integração e controle sócio-humano e tende a ser, portanto, a "extensão virtual" do espaço social propriamente dito.

O autor esclarece que no ciberespaço a máquina se constitui apenas como mediação de uma interação sócio-humana, o que deveria se constituir em uma potencialidade para a o desenvolvimento da sociabilidade humana numa perspectiva omnilateral ${ }^{4}$, na qual os indivíduos poderiam desenvolver diversas dimensões de suas capacidades humanogenéricas diante da oportunidade de acesso a uma gama de conhecimentos historicamente produzidos pela humanidade, além de poder ampliar seus potenciais intelectivos.

De fato, o desenvolvimento das tecnologias de informação e comunicação contribuiu para uma maior dinamização das relações e processos sociais no que se refere à interação desses processos com o tempo e espaço. Atividades como a comunicação entre os indivíduos, a disseminação de conhecimentos, difusão de notícias a um alcance mundial, puderam ser potencializadas diante do avanço dos recursos computacionais e de internet e da redução da distância e do tempo que essas tecnologias proporcionam.

Todavia, no âmbito da lógica de reprodução capitalista, o uso das TICs passa a potencializar as contradições intrínsecas a este sistema, tornando-se uma forma de controle sóciometabólico do capital em que o fetiche da máquina oculta e intensifica a forma estranhada desta sociabilidade (ALVES, 2011).

Nessa perspectiva, autores como Belloni (2002) e Christensen (2013) enaltecem a imprescindibilidade do uso da TICS no processo formativo dos sujeitos, diante de um contexto marcado pelas constantes transformações tecnológicas e facilidades no acesso à informação e comunicação que estariam conformando uma nova dinâmica das relações sociais. Essas transformações técnicas, econômicas e culturais estariam gerando uma nova forma de compreender o mundo que impõe novos desafios ao campo da educação.

A crença de que estaria emergindo uma "nova forma de compreender o mundo", a partir da intensificação do uso das TICs na vida social, é o principal argumento utilizado por intelectuais orgânicos, representantes da classe burguesa no campo educacional - aqui referenciamos também os organismos internacionais como a UNESCO e BM - de que a forma de ensino tradicional (diga-se, presencial) estaria ultrapassada diante da demanda por uma educação que garanta uma aprendizagem mais fluida, que valorize os conhecimentos e competências adquiridas ao longo da vida, aspectos esses considerados essenciais às novas demandas do mercado de trabalho.

Precisamos de forma mais fluida da aprendizagem como um contínuo, no qual as escolas e instituições de educação formal interajam de forma mais próxima com outras experiências educacionais menos formalizadas desde a infância e também ao longo de toda a vida. As modificações nos espaços, nos momentos e nas relações em que ocorrem a aprendizagem favorecem a formação de uma rede de

\footnotetext{
${ }^{4}$ Aqui partimos da perspectiva do desenvolvimento do homem em todas as suas potencialidades mediante a superação limitada, imposta pela sociabilidade capitalista. Tal superação só será possível com a extinção dessa sociabilidade e das formas de trabalho alienadas a elas inerentes (LESSA, 2012).
} 
espaços de aprendizagem, na qual espaços não formais e informais irão interagir com instituições formais e complementá-las (UNESCO, 2016, p. 52-53).

É diante de uma realidade marcada pela dinamicidade e efemeridade que intelectuais (RAMAL, 2012; ROCHA, 2017; MORAN, 2012; CHRISTENSEN, 2013) - defensores e propulsores das novas formas de ensino-aprendizagem - exaltam as potencialidades proporcionadas pelo desenvolvimento das TICs, sobretudo em relação aos avanços no campo da Inteligência Artificial e expansão do acesso à internet. Estes afirmam que as novas dinâmicas no âmbito das relações sociais, engendradas a partir do desenvolvimento dessas tecnologias impõem inovações nos processos pedagógicos que melhor se adequem a uma realidade cada dia mais dinâmica e efêmera. Dentre elas destacamos conceitos e métodos como Inovação Disruptiva, Bleended, metodologias ativas, ensino híbrido que são, atualmente, amplamente disseminados no campo da educação e comunicação social.

De acordo com esses teóricos, a flexibilidade do uso do tempo e do espaço, aliada a novas estratégias pedagógicas de ensino-aprendizagem, é essencial diante de um contexto socioeconômico, a nível mundial, marcado por intensas transformações e instabilidade o qual impõem ao indivíduo uma nova forma de compreender e assimilar as informações e os conhecimentos e de desenvolver competências e habilidades (profissionais e socioemocionais) necessárias aos enfrentamentos de problemas.

Em relação aos recursos pedagógicos, destaca-se a importância do uso das TICs enquanto instrumentos que possibilitam a transformação dos conteúdos e formas de aprendizagem. Na esteira dessa discussão, destaca-se, por exemplo, a importância do uso de dispositivos móveis os quais proporcionam uma aprendizagem mais individualizada na qual o aluno pode definir seu próprio tempo e ritmo de aprendizagem, o que favorece a aprendizagem ao longo da vida e; o uso das TICs enquanto meio para desenvolver competências a partir de recursos de simulação.

\footnotetext{
Los diversos dispositivos poseen propiedades peculiares que los hacen sumamente convenientes para cada labor de aprendizaje en particular. Por ejemplo, las redes sociales pueden ampliar los ejercicios de clase, pues brindan oportunidades de realizar actividades por la vía de la colaboración y la coautoría. El aprendizaje adopta formas diversas, pues, gracias al dispositivo móvil, las personas pueden consultar medios didácticos y comunicarse con los demás y crear obras, en los entornos educativos o fuera de ellos [...]. El dispositivo móvil complementa un buen método de aprendizaje y sirve para formular premisas, resolver problemas prácticos apropiados a circunstancias particulares, reflexionar y elaborar nuevos conocimientos, y adquirir nuevas competencias y aptitudes por vía de simulacros [...] (UNESCO, 2015, p. 7). ${ }^{5}$
}

\footnotetext{
5 "Os vários dispositivos possuem propriedades peculiares que os tornam extremamente convenientes para cada tarefa de aprendizado em particular. Por exemplo, as redes sociais podem estender exercícios de classe, uma vez que fornecem oportunidades para realizar atividades por meio de colaboração e co-autoria. $O$ aprendizado toma formas diferentes, pois, graças ao dispositivo móvel, as pessoas podem consultar meios didáticos e se comunicar com os outros e criar trabalhos, em ambientes educacionais ou fora deles [...]. 0 dispositivo móvel complementa um bom método de aprendizagem e serve para formular premissas, resolver problemas práticos apropriados a circunstâncias particulares, refletir e desenvolver novos conhecimentos, além de adquirir novas habilidades e habilidades através de simulações [...]" (UNESCO, 2015, p. 7, tradução nossa).
} 
Deste modo, formas de aprendizagem móvel - proporcionada a partir da mediação do uso de celulares smartphones - e; a existência de Cursos Online Abertos e Massivos (MOOCS) são enfatizados enquanto exemplos de novas experiências que possibilitam uma melhor conciliação entre os mais diversos espaços de aprendizagens através da troca de experiências entre instituições formais e outras experiências educacionais.

As principais premissas utilizadas pelos autores que analisam esta temática pautam-se na defesa da superação dos limites da sala de aula tradicional, considerada como um espaço burocrático, reduzido à ação centralizada no professor e nas aulas expositivas com estruturas curriculares rígidas, distantes da realidade, que limitam o desenvolvimento da criatividade e autonomia dos alunos.

As formas de aprendizagem tradicionais - caracterizadas, pelos intelectuais proponentes da "educação inovadora," como sendo uma educação bancária, arcaica e rígida - não condizem mais com as atuais demandas postas pela sociedade, tornando-se essencial, portanto, a reestruturação do processo formativo dos sujeitos não apenas no que se refere à gestão escolar, mas, principalmente, nas formas de reorganização dos processos educativos, desde à própria organização do espaço e do tempo de formação (aspecto esse que é medular na modalidade de ensino a distância), quanto na própria redefinição curricular e dos processos pedagógicos da aprendizagem.

No Brasil, o debate sobre a incorporação das TICs nos processos educativos ocorre desde os anos 1990. Todavia identificamos o fortalecimento do reconhecimento governamental sobre o uso de recursos tecnológicos para o processo de aprendizagem a partir da aprovação do Plano Nacional de Educação de 2014 o qual define, em suas estratégias, a promoção de mecanismos que visam a estimular a expansão dos recursos digitais no processo de ensino e aprendizagem. Podemos identificar essa prerrogativa expressa, por exemplo, nas seguintes metas:

5.4 fomentar o desenvolvimento de tecnologias educacionais e de práticas pedagógicas inovadoras que assegurem a alfabetização e favoreçam a melhoria do fluxo escolar e a aprendizagem dos (as) alunos(as), consideradas as diversas abordagens metodológicas e sua efetividade; (BRASIL, 2014, p. 58)

7.12: incentivar o desenvolvimento, selecionar, certificar e divulgar tecnologias educacionais para a educação infantil, o ensino fundamental e o ensino médio e incentivar práticas pedagógicas inovadoras que assegurem a melhoria do fluxo escolar e a aprendizagem, assegurada a diversidade de métodos e propostas pedagógicas, com preferência para softwares livres e recursos educacionais abertos, bem como o acompanhamento de resultados nos sistemas em que forem aplicadas (BRASIL, 2014, p. 62)

A partir das estratégias apontadas, evidenciamos a centralidade da utilização dos recursos das TICs para o aperfeiçoamento dos processos pedagógicos no âmbito das políticas educacionais brasileiras em consonância com as orientações internacionais. Contudo, isso não implica afirmar que houve um abandono em relação à utilização das TICs como meio de expansão do acesso aos sistemas de ensino, especificamente, no que tange aos sistemas de ensino técnico-profissional, superior e de pós-graduação stricto sensu, através da modalidade de Ensino a Distância. 
Em outubro de 2015, o MEC cria, em parceria com universidades federais e professores da educação básica, uma plataforma de Recursos Educacionais Digitais. Essa plataforma tem o objetivo de socializar recursos digitais que podem ser utilizados pelos diferentes sujeitos do campo educacional (docentes, discentes e gestores) no processo educativo. Além da socialização de materiais educativos, a plataforma visa estimular a interação e troca de experiências entre os profissionais.

Essa iniciativa visa o alcance de uma das estratégias apontadas pelo PNE (BRASIL, 2014) em relação ao fomento de criação e expansão das redes educacionais abertas e a utilização dos recursos digitais para o processo de ensino-aprendizagem.

Em 2016, o governo brasileiro publica o terceiro Plano de Ação Nacional do Brasil para o Governo Aberto elencando 16 novos compromissos do país no âmbito da Parceira Governo Aberto (OGP). Lançada em setembro de 2011, a OGP é uma iniciativa internacional firmada, inicialmente, entre oito países ${ }^{6}$ os quais firmaram um compromisso coletivo com a publicação da Declaração de Governo Aberto cujo objetivo é promover, em âmbito internacional e nacional, iniciativas que visam difundir e incentivar práticas de governança transparentes e democráticas, garantindo plano acesso à informação pública e participação social.

Nesse terceiro plano de ação, o Brasil delimita em seu sexto compromisso “[...] estabelecer novo modelo de avaliação, aquisição, fomento e distribuição de Recursos Educacionais Digitais (RED) no contexto da cultura digital" (BRASIL, 2016, p.22). Conforme afirma o documento, esse compromisso tem por objetivo desenvolver na política educacional brasileira o potencial da cultura digital, estimulando o uso de recursos educacionais digitais mediante: investimento em infraestrutura; formação docente; produção de recursos e conteúdos digitais e; estabelecer um novo modelo de avaliação, aquisição, fomento e distribuição de RED.

Todavia, será a partir da publicação do documento Estratégia brasileira para a transformação digital (BRASIL, 2018) que iremos identificar uma incorporação mais enfática dos preceitos internacionais no que se refere à adequação das políticas educacionais ao mundo digital articulada à necessidade de fomentar uma nova forma de educar e aprender.

A educação do futuro ocorrerá ao longo da vida (“lifelong learning”) e a educação continuada terá papel central na vida de um número cada vez maior de pessoas. As desigualdades que o País apresenta devem ser combatidas também quanto ao acesso e uso das tecnologias digitais, campo em que as políticas educacionais para o meio digital têm papel muito relevante (BRASIL, 2018, p. 45).

A importância da expansão dos recursos digitais e do uso da internet enquanto um importante veículo para a melhoria das políticas educacionais brasileiras é sintetizada em quatro pilares: 1) melhoria nos sistemas de gestão ao permitir a formulação de indicadores mais confiáveis e maior fluxo de informação entre gestores, diretores e docentes; 2)

\footnotetext{
${ }^{6}$ Inicialmente, afirmaram o compromisso: África do Sul, EUA, Brasil, México, Filipinas, Indonésia, Reino Unido e Noruega. Atualmente, a iniciativa conta com a participação de 75 países. Informações colhidas no Portal Parceira para o Governo Aberto. Disponível em: http://governoaberto.cgu.gov.br/a-ogp/o-que-e-a-iniciativa. Acesso em: 5 fev. 2019.
} 
possibilidade de diversificação de formas de educação continuada de professores; 3) ampliação do acesso à informação entre os discentes e; 4) garantir um melhor acompanhamento entre pais, docentes e gestores escolares, promovendo uma participação mais ativa dos primeiros na educação dos filhos (BRASIL, 2018).

O documento também destaca a importância em se expandir o uso de recursos educacionais digitais e acesso à rede de internet nas escolas públicas brasileiras; além de propor uma melhor capacitação profissional no que tange à aquisição de competências básicas em $\mathrm{TI}$, destacada enquanto um dos principais limites postos à qualificação da mão de obra brasileira.

Apesar da disseminação do discurso de que a inserção dos recursos tecnológicos no processo pedagógico visa qualificar a educação ofertada aos discentes, contribuindo para o maior compartilhamento de informações, produção de conhecimentos valorização do protagonismo dos indivíduos, não são esses preceitos que se efetivam, na prática, no âmbito da política educacional brasileira.

A utilização de tecnologias na educação brasileira reitera o caráter dualista e heterônomo desta, pois ao serem incorporadas na educação direcionada à classe trabalhadora brasileira, efetivam a estratégia de substituição dos sistemas de ensino tradicionais e de contingenciamento de gastos, os quais trazem, como principal desdobramento, a precarização desse processo educativo.

Podemos evidenciar esta tendência com a aprovação da Lei da Reforma do Ensino Médio. Com esta reforma, o governo liberou $20 \%$ da carga horária total para o turno diurno e $30 \%$ dos cursos noturnos para a realização de atividades na modalidade de ensino à distância. Esta lei autoriza, também, a utilização de recursos do Fundeb para a consolidação de parcerias com setor privado, inclusive empresas que ofertam a modalidade EaD para a integralização dos currículos nesse nível de ensino.

A autorização da utilização de parte da carga horária dos cursos de Ensino Médio na modalidade EaD - a ser utilizada, preferencialmente, sobre os conteúdos dos itinerários formativos - é justificada pelos mesmos argumentos que embasaram a expansão desta modalidade no ensino de nível superior: inovação no processo educacional com a inserção de novas tecnologias de aprendizagem; melhoria no acesso para os estudantes que moram em locais que Ihe inviabiliza a presença nas aulas de forma contínua.

Contudo, compreendemos que essa medida se constituiu em mais um ataque proferido pelo governo para o desmonte da educação pública brasileira, efetivado através do acirramento da privatização e precarização da educação pública minando, cada vez mais, o direito dos filhos da classe trabalhadora brasileira do acesso a uma educação pública de qualidade, acirrando as desigualdades educacionais que marcam o sistema educacional no país.

Diante das reflexões desenvolvidas, podemos compreender que a expansão do uso dos recursos tecnológicos nos processos de formação e qualificação profissional da classe trabalhadora, apesar de se apresentar com face da modernização e ampliação das oportunidades de acesso e aquisição de conhecimentos, evidencia uma nova tendência de precarização dessa formação. 


\section{CONCLUSÃO}

Diante de uma conjuntura marcada pelo acirramento da crise socioeconômica identificamos nos relatórios dos organismos internacionais a ênfase na defesa pelo uso das TICS enquanto principal forma de readequação do sistema de gestão das instituições de ensino - de modo a buscar novas estratégias de enfrentamento aos limites financeiros impostos em um contexto de crise econômica - e; readequação dos processos de aprendizagem, de modo que estes estejam mais alinhados à nova dinâmica do campo produtivo que passam a requisitar novas habilidades profissionais.

Em contexto de acirramento do desemprego, da flexibilização dos contratos de trabalho e precarização das condições de vida da classe trabalhadora, o foco das políticas educacionais centra-se nos processos de aprendizagens flexíveis e desenvolvimento de competências individuais e habilidades socioemocionais.

Passam a serem valorizados outros espaços e possibilidades de aquisição de conhecimentos e a relevância da aprendizagem fora das instituições formais (como, por exemplo, o espaço familiar, o ambiente de trabalho, dentre outros). Estes teriam na modalidade EaD - acompanhada pelo desenvolvimento de novas tecnologias educacionais - o suporte pedagógico mais adequado a estas novas formas de aprendizagem.

Consideramos que a inserção das Tecnologias de Informação e Comunicação ao processo de formação profissional dos sujeitos, se constitui em uma das estratégias de reprodução da ideologia dominante, pois consolida sua estratégia de reprodução em duas frentes: a primeira se constitui no estabelecimento de consenso de classes ao atender a demanda latente da classe trabalhadora por maiores níveis de formação profissional, principalmente àqueles grupos que teriam dificuldade de acesso ao sistema presencial e tradicional de ensino - aqui podemos destacar o uso das TICs através da modalidade EaD.

A segunda está relacionada à própria flexibilização do processo educativo a qual trivializa o processo de ensino e aprendizagem destituindo desse processo o seu caráter social e, consequentemente, despindo a formação desses sujeitos das possibilidades de acesso à gama de conhecimentos socialmente construídos de forma crítica.

Sob o discurso de que essa nova forma de aprendizagem contribui no desenvolvimento da autonomia e domínio dos indivíduos sobre os seus processos formativos, o que constatamos, a partir das reflexões tecidas, é que essa nova forma de aprendizagem, mediada pelo uso das TICs, se constitui em uma nova estratégia do domínio do capital sobre o processo de formação da classe trabalhadora.

Se, no modelo de produção fordista, a institucionalização da educação de massas foi fundamental para conformar um novo tipo de homem adaptado à nova ordem; no regime de acumulação flexível podemos inferir que a nova educação das massas deverá ser realizada a partir de processos de aprendizagem flexíveis, através do redimensionamento do tempo, do espaço e de estratégias pedagógicas para a formação da classe trabalhadora conforme as necessidades do capital. 
A finalização da escrita deste artigo ocorre em um contexto de pandemia da COVID-19 que escancara as contradições inerentes à sociabilidade capitalista, acirrando a crise socioeconômica do capital, que se alastra desde o segundo decênio dos anos 2000.

Nesse atual contexto o governo brasileiro busca implementar diversas estratégias na ânsia de consolidar a perspectiva de aprendizagem flexível defendida pelos organismos internacionais, sob o argumento de que a educação "não deve parar": a adoção do Ensino Remoto Emergencial nas universidades públicas; a defesa pela reabertura das escolas e adoção do ensino híbrido; a retomada do projeto de lei 3261/2015 que visa regulamentar a educação domiciliar no Brasil são alguns exemplos de como a classe dominante pode legitimar o seu projeto para "educar" a classe trabalhadora.

Porém, a própria realidade concreta escancara a insustentabilidade desse projeto e como a defesa pela ampliação do uso das TICs só será, de fato, enriquecedora para todos/as quando for articulada à luta por uma nova sociabilidade na qual as tecnologias serão utilizadas como instrumentos no processo de emancipação humana, e não no da sua alienação.

\section{REFERÊNCIAS}

ALVES, Giovanni. Trabalho e subjetividade: o espírito do toyotismo na era do capitalismo manipulatório. São Paulo: Boitempo, 2011.

BANCO MUNDIAL. Aprendizagem para todos: investir nos conhecimentos e competências das pessoas para promover o desenvolvimento. Banco Mundial, 2011 [sumário executivo].

BELLONI, Maria Luiza. Educação a distância e inovação tecnológica. In: Trabalho, Educação e Saúde, v.3, n.1, p.187-198, 2005. Disponível em: http://www.revista.epsjv.fiocruz.br/upload/revistas/r101.pdf

BEHRING, Elaine Rosseti. Brasil em contrarreforma: desestruturação do Estado e perda de direitos. São Paulo: Cortez, 2003.

BIANCHI, Álvaro. O laboratório de Gramsci: filosofia, história e política. São Paulo: Alameda, 2008.

BRASIL. Plano Nacional de Educação. Brasília (DF), 2014.

BRASIL. Instituto Nacional de Estudos e Pesquisas Educacionais Anísio Teixeira. Panorama da Educação: destaques do Education at a Glance 2016. Brasília (DF): Diretoria de Estatísticas Educacionais, 2016.

BRASIL. Estratégia brasileira para a transformação digital. Brasília (DF), 2018.

CHRISTENSEN, Clayton M. Ensino híbrido: uma nova inovação disruptiva?. Clayton Christensen Institute [sumário executivo], 2013.

DIAS, Edmundo. Revolução Passiva e modos de vida: ensaio sobre as classes subalternas, o capitalismo e a hegemonia. São Paulo: Editora José Luis e Rosa Sundermann, 2012. 
ENGUITA, Mariano. Educar em tempos incertos. Porto Alegre: Artmed, 2004.

FERREIRA, Adriano de Melo. A inovação nas políticas educacionais no Brasil: universidade e formação de professores. 2013. Tese (Doutorado em Educação)- Programa de Pós-graduação em Educação, da Faculdade de Educação da Universidade Federal de Goiás, 2013.

GRAMSCl, Antonio. Cadernos do Cárcere, volume 4. Edição e tradução de Carlos Nelson Coutinho; co-edição, Luiz Sérgio Henriques e Marco Aurélio Nogueira. 2. ed. Rio de Janeiro: Civilização Brasileira,2007. p. 241-282.

HARVEY, David. O Estado neoliberal. A condição Pós-Moderna. 17. ed. São Paulo: Edições Loyola, 2008.

KUENZER, Acácia Zeneida. Trabalho e escola: a aprendizagem flexibilizada. In: ANPED Sul - REUNIÃO CIENTÍFICA REGIONAL DA ANPED: EDUCAÇÃO, MOVIMENTOS SOCIAIS E POLÍTICAS GOVERNAMENTAIS, 11., 2016, Curitiba. Anais [...]. Curitiba: UFPR, 2016. Disponível em: http://www.anpedsul2016.ufpr.br. Acesso em: 12 jan. 2018.

KUENZER, Acácia Zeneida. Da dualidade assumida à dualidade negada: o discurso da flexibilização justifica a inclusão excludente. Educação e Sociedade, Campinas, v. 28, n. 100, Especial, p.1153-1178, 2007. Disponível em:

https://www.scielo.br/j/es/a/sB3XN4nBLFPRrhZ5QNx4fRr/abstract/?lang=pt. Acesso em: 12 jan. 2018.

LESSA, Sérgio. Trabalho e Proletariado no capitalismo contemporâneo. São Paulo: Cortez, 2007.

LESSA, Sérgio. Mundo dos homens: trabalho e Ser Social. São Paulo: Instituto Lukács, 2012. $3^{\mathrm{a} e d .}$

LIMA, Kátia. Contra-reforma na educação superior: de FHC a Lula. São Paulo: Xamã, 2007.

MANCEBO, Deise. Educação Superior no Brasil: expansão e tendências (1995-2014).

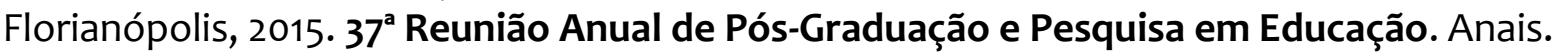
Disponível em: http://www.anped.org.br. Acesso em: 02 jun. de 2017.

MANDEL, Enesto. A aceleração da inovação tecnológica. In: MANDEL, Enesto. 0 capitalismo tardio. São Paulo: Abril Cultural, 1982.

MASSUDA, Yaneji. A sociedade da informação como sociedade pós-industrial. Tradução do inglês de Kival Charles Weber e Angela Melin. Rio de Janeiro: Ed. Rio, 1982.

MORAN, José Manuel. Contribuições para uma pedagogia da educação on line. In: Educação On line: teorias, práticas, legislação, formação corporativa. 4.ed. São Paulo: Edições Loyola, 2012. 
RAMAL, Andrea Cecília. Educação com tecnologias digitais: uma revolução epistemológica em mãos do desenho instrucional. In: Educação On line: teorias, práticas, legislação, formação corporativa. 4. ed. São Paulo: Edições Loyola, 2012.

ROCHA, Enilton Ferreira. O “patinho feio" EaD se transformando na "bola da vez?". Disponível em:

http://abed.org.br/arquivos/o_patinho_feio_ou_bola_da_vez_ENILTON_ROCHA.pdf Acesso em 10 jan. de 2017.

SCHAFF, Adam. A sociedade informática: as consequências sociais da segunda revolução industrial/ Adam Schaff; tradução Carlos Eduardo Jordão Machado e Luiz Arturo Obojes. 4. ed. São Paulo: Editora Universidade Paulista: Brasiliense, 1995.

SGUISSARDI, Valdemar. Universidade brasileira no século XXI. São Paulo: Cortez, 2009.

UNESCO. Repensar a educação: rumo a um bem comum mundial? Brasília: Unesco Brasil, 2016.

UNESCO. El futuro del aprendizaje: por qué deben cambiar el contenido y los métodos de aprendizaje em el siglo XXI? In: INVESTIGACIÓN y prospectiva em educación: documentos de trabajos. Unesco, 2015.

\footnotetext{
Taise Cristina Gomes Clementino Negreiros

Assistente Social, formada pela Universidade Federal do Rio Grande do Norte (DESSO/UFRN); mestre em Serviço Social pelo Programa de Pós -Graduação em Serviço Social da Universidade Federal do Rio Grande do Norte (PPGSS/UFRN) e Doutora pelo Programa da Pós-Graduação em Serviço Social pela Universidade Federal de Pernambuco (PPGSS/UFPE). Atualmente, professora Adjunta do Departamento de Serviço Social da Universidade de Brasília (SER/UNB) e integrante do Grupo de Estudos Marxistas e Pesquisas em Política Social e Trabalho (GEMPP).
} 